\title{
MÁS ALLÁ DE UNA SEGUNDA REELECCIÓN: LÍMITES AL PODER DE REFORMA EN TIEMPOS DE CONSTITUCIONALISMO
}

\author{
Beyond a Second Re-Election: Limits on the Power of Reform in \\ Times of Constitutionalism
}

\section{Abraham Zamir Bechara Llanos ${ }^{1}$}

Fecha de Recepción: Noviembre 3 de 2014

Fecha de Aceptación: Noviembre 10 de 2014

SUMARIO: 1. Introducción, metodología; 2. Desarrollo; 2.1 El fenómeno jurídico de la sustitución de la constitución y sus principales rasgos en la justicia constitucional; 2.2 El referéndum como mecanismo de

participación ciudadana y sus ingenios reeleccionistas; 2.3 La relación de tensión existente entre el concepto de democracia y la reelección presidencial en Colombia abordada desde el constitucionalismo; 3. Conclusiones; 4. Referencias bibliográficas.

\footnotetext{
${ }^{1}$ Abogado y Especialista en Derecho Constitucional Universidad Libre. Ex Becario Unilibre para estudios de posgrado. Maestrando en Derecho Modalidad Investigación-línea: asuntos Públicos y Administración de Justicia, Universidad del Norte. Profesor investigador tiempo completo y Coord. de investigaciones Facultad de Derecho. Universidad de San Buenaventura Cartagena. abechara@usbctg.com
} 


\section{COMO SE CITA ESTE ARTÍCULO (APA 6)}

Bechara Llanos, A. Z. (2014) Más allá de una segunda reelección: límites al poder de reforma en tiempos de constitucionalismo. (Y. Carrillo De la rosa, Ed.) Revista Jurídica Mario Alario D'Filippo, VII (13), pág. 18-26

\section{RESUMEN}

El presente artículo construye la idea central de determinar por qué una posible segunda reelección presidencial en Colombia desbordaría los límites competenciales del poder de reforma. Para ello utilizaremos, como referente teórico, la teoría de la sustitución de la Constitución, como una tensión existente desde el constitucionalismo democrático. Nuestra propuesta gira sobre tres componentes principales, a saber: (i) El fenómeno jurídico de la sustitución de la constitución y sus principales rasgos en la justicia constitucional; (ii) El referéndum como mecanismo de participación ciudadana y sus ingenios reeleccionistas, y (ii) La relación de tensión existente entre el concepto de democracia y la reelección presidencial en Colombia, abordada desde el constitucionalismo. Este estudio propone un debate crítico, que permita construir herramientas teóricas para una discusión razonable.

\section{PALABRAS CLAVE}

Límites constitucionales, poder de reforma, constitucionalismo democrático, sustitución de la Constitución, reelección presidencial.

\section{ABSTRACT}

This article builds the central idea to determine why a possible second presidential reelection in Colombia would exceed the jurisdictional limits of power reform. We will use as a benchmark theory, the theory of substitution of the Constitution, as a tension from the democratic constitutionalism. Our proposal focuses on three major components, namely: (i) The legal phenomenon of replacing the constitution and its main features in the constitutional justice; (Ii) The referendum as a mechanism for citizen participation and ingenuity of those who support the re-election, and (ii) The relationship of tension between the concept of democracy and the presidential election in Colombia, approached from constitutionalism. This study proposes a critical debate that can build theoretical tools for a reasonable discussion.

\section{KEYWORDS}

Constitutional limits, to reform, democratic constitutionalism, replacing the Constitution, presidential reelection. 


\section{INTRODUCCIÓN}

El Estado colombiano, como Estado social de derecho, procura por el reconocimiento y la protección especial de los derechos fundamentales de todos sus ciudadanos. Bajo esta precisa se estructura la idea que, para el cumplimiento de estos fines la norma fundamental de todo Estado, es decir, la Constitución política, se encuentre conformada de mecanismos que le permitan erigirse como un cuerpo sólido, fuerte y rígido. En aras de que sus valores, principios y preceptos fundamentales no sean modificados por el poder político representativo, de un mandato general superior, como lo es el de la soberanía popular.

En este orden de ideas, la Constitución y su rigidez, va a estar denotada por los mecanismos de reformas contra sus propias disposiciones, es decir, diferenciados de los procedimientos o mecanismos para reformar o expedir leyes ordinarias, ya que la Constitución por su solo carácter de servir de fundamento a todo el sistema jurídico colombiano, debe gozar de un procedimiento de reforma más extenso y de difícil realización como el de las leyes generales. Esto como primera medida, tenemos además que la constitución se consolida sobre una serie de valores, principios y derechos fundamentales, que se construyen a través del mandato que da el pueblo, a una Asamblea Nacional Constituyente, que como su nombre lo indica esta investida de plenos poderes con el fin principal de crear la constitución. Por otro lado, una vez creada la Constitución, se conforman poderes constituidos, como el poder político, constituido en cabeza del presidente de la república, para que este por vía de representación, gobierne los intereses superiores del pueblo.

Hasta aquí, está claro que cada uno de los dos poderes, el constituyente y el constituido o político, cumplen un papel armonizador en la ardua labor de construir la democracia. La dificultad se presenta cuando una vez creada la Constitución por el poder constituyente, esta se altere, modifique, o destruya sus principales preceptos y postulados fundamentales que le dan vida a la misma, y esto podría presentarse, en el caso particular de estudio, con la figura del referendo reeleccionista, cuando el presidente de la república, claro poder constituido, sustituya la constitución para beneficio propio, para que su período presidencial constitucional se extendido por cuatro años más. Lo interesante de este estudio es descifrar los enclaves de las dos figuras, tanto la de la reelección presidencial, como la de la sustitución de la constitución, y así encontrar los alcances y límites que permitan evidenciar o no, que la figura de la reelección presidencial es un claro fenómeno de sustitución de la constitución, con relación a esto TOBO RODRIGUEZ manifiesta:

Sustituir la Constitución es incorporar elementos que reemplacen a los originalmente adoptados por el constituyente; así, para establecer si hay o no sustitución se debe considerar tanto los principios y valores contenidos en la constitución, como aquellos que surgen del bloque de constitucionalidad, para determinar si los principios anteriores y los nuevos son opuestos o integralmente diferentes, hasta llegar a ser incompatibles. La sustitución será total si la Constitución como un todo es reemplazada por otra, y será parcial cuando un eje definitorio de su identidad resulte reemplazado por otro integralmente diferente. (2012.p. 276)

Es así, que con este proyecto de investigación se pretende demostrar las tensiones que existen 
entre los conceptos de democracia, constitucionalismo y populismo, frente al pasado intento fallido de Referendo Reeleccionista que se llevó a cabo en nuestro país. El Referendo Reeleccionista Presidencial del año 2010 buscaba realizar una reforma a la Constitución Política de Colombia, para que fuera posible que un mismo candidato presidencial estuviera al mando por tres períodos consecutivos, pues años atrás, ya había sido aprobada la reelección inmediata. Sin embargo, este mecanismo de participación ciudadana, no fue exitoso debido a vicios de forma y de fondo que impidieron que se llevara a cabo, tales como cambios a última hora en el contenido del artículo, excesos en los recursos para la financiación, inconvenientes con las firmas recaudadas, entre otros que le dieron punto final a esta iniciativa que para algunos, nunca tuvo que presentarse pues era un notorio golpe a la democracia y la misma Constitución.

\section{METOdOLOGÍA}

Es así teniendo en cuenta lo anterior que llegamos a la siguiente formulación de nuestro problema de investigación: ¿Sustituye la Constitución Política, el hecho de que exista una segunda reelección presidencial en Colombia? ¿Cuáles son los límites constitucionales al poder de reforma? ¿Decanta la teoría de la sustitución constitucional un imperativo neo-democrático para el estado constitucional?

El hecho de que exista una segunda reelección en Colombia desborda los límites constitucionales al poder de reforma, instituidos como poder constituido por el constituyente, es así que un desconocimiento de los principios y valores fundantes del entendido general de la Constitución, alteraría su sentido a tal punto de no reformarla sino de sustituirla. Principalmente encontramos un fuerte eco en nuestro estudio, ya que el tema de la reelección presidencial como tópico de una democracia constitucional, debe ser abordado con un sentido crítico y reflexivo, pero sobre todo de los orígenes del poder de reforma, y las diferencias y semejanzas entre poder constituyente y poder constituido, herramientas teóricas claves para determinar si se sustituye o no la Constitución hasta tal punto de refundarla o crear una nueva Constitución.

Nos propusimos realizar la investigación con varios enfoques, ellos son: descriptivo, bibliográfico, explicativo, de tipo cualitativo sobre el análisis a la figura del referéndum reeleccionista en Colombia como sustitución de la Constitución. Se presenta como una respuesta de salida a la problemática de los límites del poder de reforma y el poder de revisión inmerso en la misma carta de derechos, como un fenómeno que implica un desconocimiento de los preceptos descritos por el constituyente y los alcances en la utilización de mecanismos propios de participación ciudadana como el referéndum utilizados para reformar el texto constitucional.

\section{DESARROLLO}

\subsection{EL FENÓMENO JURÍDICO DE LA SUSTITUCIÓN DE LA CONSTITUCIÓN Y SUS PRINCIPALES RASGOS EN LA JUSTICIA CONSTITUCIONAL}

El fenómeno de la sustitución de la Constitución es un acontecimiento de reciente configuración en el derecho constitucional, principalmente se ha conformado de estudios realizados por autores 
europeos, dedicados al estudio de la política y de la constitución. Indudablemente estas dos acepciones, han ido caminando de la mano en su gestación a lo largo de los Estados, y de la inclusión de la ley en el Estado de derecho, al pasar por la noción de Estado social de derecho hasta llegar al postulado del Estado constitucional de derecho donde se gesta la justicia que toma su propio nombre (justicia constitucional). Por otro lado el concepto de sustitución de la constitución va estrechamente ligado al concepto de reforma a la constitución, como un ejercicio concerniente al poder constituyente primario, que es el pueblo, y al poder constituyente derivado, que es la Asamblea Nacional Constituyente. Al respecto PEDRO DE VEGA ha dicho:

A través de la reforma, se produce el acoplamiento de la Constitución con su propia realidad, y se impide que la normativa fundamental quede reducida a un conjunto de fórmulas sin proyección histórica y práctica ninguna, la revisión de la constitución, lejos de interpretarse como un instrumento de deterioro del ordenamiento fundamental, debe entenderse como su primera y más significativa defensa. Reformar la Constitución no significa destruirla, sino, simplemente, acoplarla a la realidad histórica, sin que pierda su identidad como estructura conformadora del Estado. La destrucción de la Constitución es tarea que no corresponde al poder de revisión, sino al poder constituyente. (1985. p. 6869)

Teniendo claro además, como opera el poder de reforma a la constitución, podemos observar que el constituyente primario se configura bajo la potestad soberana del pueblo mismo, lo que significa que una vez configurados los demás poderes constituidos, como el legislativo, estos no pueden superar el ámbito de sus competencias y alterar sustancialmente el texto de la constitución.

Otro aspecto fundante en la posición de la Corte Constitucional, es el concepto mismo de la sustitución constitucional, y que de manera sencilla se ha expresado, C-551 de 2003. Que sustituir la Constitución además de introducir un nuevo texto en ella es, alterar su integralidad de conjunto, es decir que el sentido de la Constitución como un conjunto de normas superiores que indican hacia dónde va la vida política, social, económica y jurídica de un estado se cambiado por otro.

Finalmente la sustitución de la constitución puede ser resuelta por los principios y valores que ella misma presenta, ya que estos pueden ser cotejados con otros que presenten rasgos de legitimidad así no lo sean, porque se encuentren abiertamente separados de la orientación de conjunto que expresa la carta fundamental de derechos. También la jurisprudencia Constitucional, se ha orientado a establecer los criterios de sustitución constitucional, que determine en qué casos puntuales existe una sustitución, del cuerpo o parte del cuerpo de la constitución nacional, esto además se refuerza con la hipótesis de considerar que cuando se estudian demandas contra los actos reformatorios de la Constitución la Corte además de entrar a estudiar aspectos formales, mire aspectos materiales, precisamente como lo indican los atinentes al de la sustitución constitucional.

\subsection{EL REFERÉNDUM COMO MECANISMO DE PARTICIPACIÓN CIUDADANA Y SUS INGENIOS REELECCIONISTAS}

Indudablemente unos de los principales avances de la Constitución Política de 1991 ha sido el de la inclusión de la democracia participativa, en el orden nacional de los colombianos. La Carta de Derechos que entró en vigencia en la década de los noventa, supera la ya conocida teoría de la representación o representatividad, inspirada por las teorías contractualitas europeas, fundamentalmente en la obra de ROUSSEAU, que en el 
contrato social esgrimo, que si los ciudadanos de un estado querían superar el viejo estado de naturaleza, en la sociedad no estaba sometida a regla alguna, estos debían ceder a una parte de sus intereses para que un ente ficticio superior llamado estado administrara su intereses, pero como opera aquí la teoría de la democracia representativa, cuando se dan cuenta además que una persona igual a ellos pero en condiciones y calidades distintas llamada gobernante, sería la cabeza visible del estado.

Bajo esta premisa, la evolución de la teoría constitucional y del estado, permitió que en Colombia con la Constitución de 1991 se introdujera, la democracia participativa, que va estrechamente ligada a los mecanismos de participación ciudadana. Con relación a esta postura GUILLERMO REYES ha planteado:

El nuevo ordenamiento Jurídico Constitucional consagra un estilo de democracia que facilita el acceso ciudadano a la participación directa en la toma de decisiones, no restringida al escenario electoral. Es la denominada democracia participativa y pluralista. Cabe destacar que el principio de participación no se agota en estas formas, por cuanto se halla también en defensa y promoción de los derechos sociales, económicos, culturales y colectivos; en el control de la gestión pública y en la discusión de los planes de desarrollo, entre otros puntos.(2004.p.676)

Es así, que en su concepto el referendo, se posiciona como uno de los mecanismos de participación ciudadana, ya que por intermedio de él, se convoca al pueblo para que por medio de votación directa apruebe o rechace un proyecto de norma, o para que derogue o no una norma que se encuentra vigente. La Corte Constitucional se ha referido al carácter del referéndum en los siguientes términos:

En el uso contemporáneo del termino referéndum, se presume la existencia de un acto jurídico en vigencia, que queda sometido al veredicto del cuerpo electoral, el cual decide si el acto jurídico se mantiene en vigencia o es abrogado o derogado. También se comprende el término en el sentido actual, según el cual se emplea para someter a la decisión de cuerpo electoral formativas importantes, con un cierto contenido emotivo, como el referéndum sobre el divorcio en varios países, o políticas públicas de gran relevancia y alcance. Hoy en día el referéndum tiende a ser considerado como uno de los principales instrumentos de la democracia directa o participativa, en cuanto permite que el cuerpo electoral tome parte inmediatamente y de forma vinculante en los grandes procesos decisorios. Cabe agregar que por cuestiones de seguridad jurídica internacional y por doctrina jurídica desde la época romana, se considera que el referéndum no tiene vigencia retroactiva ${ }^{2}$.

El referéndum es bien sabido que es un mecanismo de participación ciudadana, pero en el estudio particular que realizamos, el caso de la reelección presidencial el referéndum cobró un interés y protagonismo especial, en la vida política y pública colombiana, ya que por medio de este mecanismo, se le pediría directamente al pueblo para que tomara la decisión de avalar un segunda reelección presidencial, y con esto un hecho sin precedentes en la historia de constitucionalismo colombiano. El principio de participación no se agota en los mecanismos de participación política, ya que el ciudadano pasa a ser sujeto activo y no solo portadores de intereses particulares, sino que

${ }^{2}$ Corte Constitucional, Sentencia C-180 de 1994. Magistrado Ponente: HERNANDO HERRERA VERGARA. 
está autorizado para desarrollar jurídicamente intereses de orden social, sean colectivos o difusos, de los que también es portador del interés general que se manifiesta en la procura de la legalidad. (FANDIÑO, 2003.p. 13)

\subsection{LA RELACIÓN DE TENSIÓN EXISTENTE ENTRE EL CONCEPTO DE DEMOCRACIA Y LA REELECCIÓN PRESIDENCIAL EN COLOMBIA ABORDADA DESDE EL CONSTITUCIONALISMO}

La democracia puede definirse de manera general como el gobierno de las mayorías, y en este entendido existirá democracia cuando las mayorías de un pueblo son representadas por sus gobernantes, en los órganos de poder. Esta noción era la clásica, usualmente utilizada para diferenciar los gobiernos democráticos de los autoritarios y totalitaristas. Pero el concepto de democracia ha evolucionado a la par del propio Estado constitucional, entendido como aquel Estado, en el que los derechos fundamentales van a estar protegidos y garantizados un por un juez especializado o juez de constitucionalidad. Y dicha evolución se ha orientado a una variación del concepto de democracia, que más bien lo complementa, y es que la democracia es hoy entendida no solo como el gobierno de las mayorías, sino en el gobierno donde las mayorías no desplieguen los intereses superiores legítimos de las minorías representadas popularmente.

Por estas razones existirá democracia, cuando el equilibrio entre las mayorías y minorías representadas en los órganos de poder político sean igualmente garantizadas e iguales en sus derechos y libertades públicas. En dicho orden, la democracia se encuentra relacionada tanto conceptual como normativamente con el concepto de justicia constitucional, como aquella en que los valores superiores, y principios fundantes de un estado son protegidos por un órgano perteneciente a la rama judicial del poder público, imparcial y distinto al órgano legislativo, encargado de proteger la supremacía, guarda e integridad de la constitución, estamos hablando de las cortes o tribunales constitucionales. Cabe observar la posición de GIANCARLO ROLLA sobre el papel de la justicia constitucional:

La relación entre justicia constitucional y derechos fundamentales de la persona se puede afrontar analizando también, el papel que ejercen los tribunales constitucionales en la difusión, generalización y en la implementación de los derechos reconocidos y tutelados como fundamentales. Ello es así porque cuando un juez constitucional decide sobre un recurso evalúa en verdad un caso particular, es decir, asegura la protección del derecho concreto del demandante; pero, al mismo tiempo, al suministrar una determinada interpretación, introduce una regla general que puede actuar como precedente, esto es, orienta los comportamientos futuros tanto del mismo juez constitucional como de los jueces ordinarios y el legislador. (2002.p.368-369)

En el Estado constitucional en sin lugar a dudas, donde se consolida la democracia, aplicando la formula en equilibrio, de las mayorías con las minorías, esta se puede optimizar en función de los derechos fundamentales, nos preguntamos si el imaginario colectivo a favor de la democracia se resquebrajaría, con un tercer mandato presidencial consecutivo, otra pregunta que podría gestarse al respecto es, si es gobierno conforme al sentido democrático de renovación y perpetuidad de sus instituciones, una mandatario presidencial que permanezca en el poder por más de doce años, 
como era la pretensión del señor Ex-presidente ALVARO URIBE VELEZ. Surgiendo además una tercera pregunta, esta segunda reelección presidencial no desdibujaría la intención original del constituyente a la que el mandato presidencial no excediera los cuatro años.

La problemática, también es fundamentada desde el escenario político, ya que en ciencia política, los actos públicos gubernamentales, se diferencian de los actos particulares y privados, de si estos son utilizados en un beneficio general y colectivo, precisamente a los que se representan, que son el pueblo y la sociedad colombiana. Conjuntamente se relacionan dos conceptos más a la discusión, y son los conceptos de legitimidad y legalidad, los cuales erigen la determinación del uso del poder político en aras de los fines colectivos. El primer concepto el de legitimidad, se refiere a si el gobernante ostenta su mandato a través de los medios idóneos para que se configure la democracia, como lo es el voto como medio de elección popular. Como segundo elemento se erige la legalidad como la observancia de las condiciones jurídicas existenciales para que el poder político cumpla sus fines y se complemente con la participación ciudadana de los electores, a través de los mecanismos de participación ciudadana, que en el objeto de examen, es el referéndum, y en que los ciudadanos pueden tomar decisiones que afecten o preserven sus propios intereses, como se dio con el proceso pro-reelección.

Teniendo en cuenta lo anterior planteado, vemos que el fenómeno de la reelección presidencial en Colombia, es un hecho político, que tiene implicaciones jurídicas, o para expresarlo en otros términos, la reelección despliega dos componentes arriba mencionados como son: el de la legitimidad política, y el de la legalidad meramente en plano jurídico, nuestro estudio pretende afrontar el problema de la relación de tensión directamente con el concepto de democracia, y si la reelección como medio de permanencia en el poder político, como es el caso en mención la segunda reelección, sustituye abiertamente la carta política de derechos nacional, o constitución del Estado colombiano. Nuestro interés es aportar herramientas de inferencia lógica, que permitan enriquecer el debate de construcción al respecto del problema que aquí evidenciaremos, y una vez identificado solucionar la problemática que esclarezca el panorama, que una vez propuesta la reelección presidencial quedó en el despliegue de toda la actividad de la soberanía popular a través del referéndum, en la consecución de los fines establecidos con dicha propuesta.

En este entendido, cobra un papel primordial los derechos fundamentales dentro de un Estado constitucional democrático, debido a que estos derechos de especial jerarquía por encontrarse en los textos constitucionales van a permitir el establecimiento de verdaderos límites al poder de reforma del texto fundamental de un Estado, el interrogante final surge como una posición contraria a la idea de un poder de reforma ilimitado de los cuerpos constitucionales, debido a que si bien no deben existir clausulas pétreas dentro de los mismos, el poder de reforma no puede verse desbordado por intereses políticos de carácter personal.

\section{CONCLUSIONES}

Es evidente que una segunda reelección presidencial desborda los límites competenciales al poder de reforma, generando sin ninguna duda tensiones, entre el constitucionalismo y la democracia. Son varios aspectos que destacamos, en primer lugar el poder de reforma, como poder constituido 
tiene unos límites concretos debido a que el constituyente lo consagro así, para que este una vez constituido no pretendiera convertirse en un poder absoluto, tesis que se rompe con la construcción de una reelección presidencial por segunda vez, dado a que los factores reales del poder y de la democracia son maniatados por intereses personales de corte individual generando un menoscabo directo del carácter formal de la democracia.

Como segunda medida de conclusión, presentamos que si bien la teoría de la sustitución de la Constitución no se encuentra totalmente desarrollada por nuestro ordenamiento jurídico colombiano, si se hace extensible su validación por parte de la jurisprudencia de la Honorable Corte Constitucional, en toda discusión frente a una posible sustitución del entendido de la Constitución, se pone de presente que los rasgos comunes para identificar dicho juicio de sustitución, son la alteración de la axiología misma de la carta política nacional, nos referimos a sus principios y valores superiores.

\section{REFERENCIAS BIBLIOGRÁFICAS}

DE VEGA, P. (1985) “Temas clave de la constitución española. La reforma constitucional y la problemática del poder constituyente". Tecnos, Madrid. España.

FANDIÑO, J. (2003) "La participación ciudadana en la administración pública". Editorial leyer. Bogotá, Colombia.

REYES, G. (2004) “El nuevo orden político y electoral en Colombia”. Editorial Legis. Primera edición, Bogotá, Colombia.

ROLLA, G. (2002) “El papel de la justicia constitucional en el marco del constitucionalismo contemporáneo". En: Tribunales y justicia constitucional. Memoria del VII congreso iberoamericano de Derecho Constitucional. Primera Edición, Universidad Nacional Autónoma de México. México, D.F.

TOBO, J. (2012) “La Corte Constitucional y el control constitucional”. Cuarta Edición, Editorial Ibáñez, Bogotá, Colombia.

CORTE CONSTITUCIONAL, Sentencia C-180 de 1994. Magistrado Ponente: Hernando Herrera Vergara. 